\title{
La consciencia histórica e intrahistórica en Miguel de Unamuno
}

\author{
Emanuel José Maroco dos Santos \\ Becario de la Fundação para a Ciência e a Tecnologia, Lisboa \\ Universidad de Salamanca, Facultad de Filosofía \\ maroco.dos.santos@gmail.com
}

\section{Contextualización teórica del problema}

En Unamuno, la primera acepción de la idea de consciencia como gran tema de interés filosófico está referida a la colectividad. Es la consciencia colectiva o, si se quiere, el espíritu del pueblo, el Volksgeist para utilizar la terminología hegeliana, la que constituye el centro de las preocupaciones filosóficas del autor durante la primera etapa de su formación intelectual (1884-1897). Lo atestiguan los ensayos que componen su En torno al casticismo, publicados por primera vez entre el invierno y la primavera de 1895, así como su novela Paz en la guerra, de 1898. Pese al hecho de que, durante dicha etapa, lo característico del pensamiento unamuniano consiste en identificar el concepto de consciencia colectiva con la categoría de intrahistoria, en detrimento del concepto de historia que es manifiestamente infravalorado ${ }^{1}$, lo cierto es que en

${ }^{1}$ «Las olas de la historia, con su rumor y su espuma que reverbera al sol, ruedan sobre un mar continuo, hondo, inmensamente más hondo que la capa que ondula sobre un mar silencioso y a cuyo último fondo nunca llega el sol. Todo lo que cuentan a diario los periódicos, la historia toda del "presente momento histórico", no es sino la superficie del mar, una superficie que se hiela y cristaliza en los libros y registros, y una vez cristalizada así, una capa dura, no mayor con respecto a la vida intrahistórica, que esta pobre corteza en que vivimos con relación al inmenso foco ardiente que lleva dentro. Los periódicos nada dicen de la vida silenciosa de los millones de hombres sin historia que a todas 
su pensamiento posterior (concretamente a partir de 1914 y con mayor incidencia a partir de 1924), como consecuencia de su destitución como rector y de su exilio voluntario -esto es, durante la tercera etapa de su formación intelectual (1914-1930)-, el concepto de historia gana inversamente preponderancia con respecto al de intrahistoria ${ }^{2}$, lo que puede observarse en sus obras La agonía del cristianismo, de 1924, y Cómo se hace una novela, de 1927. La síntesis de este movimiento antitético, del cual es expresión su cuarto período de formación intelectual (1931-1936), surge con el regreso de Unamuno a España, en el año 1930². Asimismo, asumiendo que en el trasfondo del pensamiento unamuniano el concepto de consciencia colectiva debe ser identificado con las nociones de historia e intrahistoria, podríamos afirmar que la intrahistoria representa el espíritu del pueblo que vive de forma inconsciente en la consciencia de una determinada comunidad y que a contrario sensu la historia consiste en esa misma idiosincrasia o espíritu del pueblo, pero ahora bajo una forma no viviente, cristalizada en libros y registros.

El paso de la consciencia colectiva a la consciencia individual se da en el año de 1897. A partir de entonces, y debido a su crisis espiritual, la preocupación unamuniana dejará de centrarse en los problemas de la consciencia colectiva, es decir, de España, para centrarse

las horas del día y en todos los países del globo se levantan a una orden del sol y van a sus campos a proseguir la oscura y silenciosa labor cotidiana y eterna, esa labor que como la de las madréporas suboceánicas echa las bases sobre que se alzan los islotes de la historia. Sobre el silencio augusto, decía, se apoya y vive el sonido; sobre la inmensa humanidad silenciosa se levantan los que meten bulla en la historia. Esa vida intra-histórica, silenciosa y continua como el fondo mismo del mar, es la sustancia del progreso, la verdadera tradición, la tradición eterna, no la tradición mentida que se suele ir a buscar al pasado enterrado en libros y papeles y monumentos y piedras» (Unamuno 1966; I, 793).

2 «¿Cuál fué el Sócrates histórico, el de Jenofonte, el de Platón, el de Aristófanes? El Sócrates histórico, el inmortal, no fué el hombre de carne y hueso y sangre que vivió en tal época en Atenas, sino que fué el que vivió en cada uno de los que le oyeron, y de todos estos se formó el que dejó su alma a la humanidad. Y él, Sócrates, vive en ésta» (Unamuno 1969; VII, 318-319).

${ }^{3}$ «"Descubrirnos a España digo -os decía-, porque si es cierto, como por muchos se nos asegura, que su mayor riqueza material en su subsuelo se esconde esquiva mientras araña el labriego con el tradicional arado la ligera capa que la recubre y vela, en su subsuelo espiritual también, en los no escudriñados soterraños de su cotidiana vida colectiva yace tal vez el veneno de su renovación futura mientras seguimos arañando con nuestra crítica y apologética en las humosas glorias de su capa histórica, tenéis que descubrir a nuestro pueblo tal como por debajo de la historia vive, trabaja, espera, ora, sufre y goza". Sólo tengo que rectificar ahora el mal sentido que entonces daba, erradamente, a lo histórico. Lo que en uno de mis ensayos de En torno al casticismo llamé la intrahistoria, es la historia misma, su entraña» (Unamuno 1971; IX 448). 
en los problemas de la consciencia individual, sobre todo en lo que respecta a los temas existenciales de la mortalidad y finalidad de las almas individuales. Con el mencionado paso, los conceptos de historia e intrahistoria antes vinculados a la consciencia colectiva darán origen a las nociones de subjetividad carnal y subjetividad histórica, de tal forma que la consciencia individual gana una doble acepción en su referencia al hombre viviente e histórico.

Consciencia: subjetividad carnal o intrahistórica

Si se tiene en consideración el ensayo Civilización y cultura, 1892, pronto se hará patente que, para Unamuno, la consciencia viviente tiene su origen en la dialéctica que mantienen entre sí los conceptos de mundo interior y mundo exterior. Pero al sostenerlo no queremos afirmar, como parece sugerir F. Meyer, que la consciencia sea, en su sentido primero y radical, la mencionada dialéctica o, en sus palabras, «la envoltura de este drama» ${ }^{4}$. Nos alejamos de dicha interpretación porque Unamuno, en el mencionado texto, hace una distinción clara entre el juego interioridad-exterioridad y el núcleo en que se desarrolla dicho juego. De este modo, siguiendo al propio autor, la consciencia es, en un primer momento, el local donde se desarrolla tal lucha, su núcleo $y$, después, la propia lucha en tanto cuanto se constituye como fuente alimentaria del referido núcleo. En este aspecto, no podemos pasar por alto el hecho de que la aceptación unamuniana de la tesis de la subjetividad del ser, que expresa el esse est percipi berkeleyano, supone la negación del noúmeno kantiano, de tal forma que la exterioridad y la interioridad están siempre referidas al sujeto del conocimiento y, por tanto, a la consciencia. Ahora bien, si el mundo exterior, al igual que el mundo interior, es propiedad del sujeto cognoscente, los procesos complementarios de naturalización y espiritualización tienden a

${ }^{4}$ «La conciencia de sí no es, pues, uno de los actores de un drama que enfrenta al yo y al mundo, sino que, en cierto modo, es la envoltura de este drama: la conciencia de sí es el lugar mismo del drama o, mejor aún, es el drama mismo; es esencialmente, por tanto, un puro conflicto, un ser que consiste en un proceso de lucha, un ser agónico» (Meyer 1962; 67-68). 
aumentar el núcleo de significaciones de la consciencia intra-histórica: por el primero, el mundo circundante de la vida naturaliza la consciencia individual, aportando ad intra un conjunto de significaciones exteriores; mientras que por el segundo, la consciencia individual espiritualiza el mundo circundante de la vida, aumentando ad extra el abanico de referencias del sujeto cognoscente. Es precisamente por este proceso complementario e ininterrumpido que la consciencia individual se constituye y enriquece.

Del ambiente exterior se forma el interior por una especie de condensación orgánica, del mundo de los fenómenos externos el de la conciencia, que reacciona sobre aquél y en él se expansiona. Hay un continuo flujo y reflujo difusivo entre mi conciencia y la naturaleza que me rodea, que es mía también, mi naturaleza; a medida que se naturaliza mi espíritu saturándose de realidad externa espiritualizo la naturaleza saturándola de idealidad interna. Yo y el mundo nos hacemos mutuamente. $\mathrm{Y}$ de este juego de acciones y reacciones mutuas brota en mí la conciencia de mi yo, mi yo antes de llegar a ser seca y limpiamente yo, yo puro. Es la conciencia de mí mismo el núcleo del recíproco juego entre mi mundo exterior y mi mundo interior. Del posesivo sale el personal (Unamuno 1966; I, 992).

En Unamuno, como hemos señalado, la consciencia viviente es un núcleo que se constituye y acrecienta asintóticamente en el tiempo a partir de la dialéctica interior-exterior. Aquí, la apertura al mundo circundante de la vida está repleta de significaciones, ya que, por ella, el hombre unamuniano percibe el terminus de su existencia a través de la anticipación de su propia muerte. Este hecho es importante, dado que la incorporación de la teoría spinoziana del conatus (ver Ética, Parte III, Caps. 6-9) como nervio fundamental de la antropología del autor tendrá consecuencias decisivas en la concepción de la consciencia como dolor. En este aspecto, aceptamos como buena la tesis de Blanco Aguinaga, que a finales de la década de los 50 afirmó que la consciencia en Unamuno no es algo meramente presentacional y abstracto sino 
algo concreto y carnal, producto del dolor ${ }^{5}$. Interpretación que es tanto más significativa cuanto el autor se rebela contra el cogito cartesiano y el yo-puro fichteano, considerados por él expresiones máximas del racionalismo moderno, que se edifica y configura a priori a partir del olvido del enraizamiento humano de las coordenadas del tiempo y del espacio. En esta concepción de consciencia como dolor, no podemos dejar de referirnos a tres influencias decisivas en la formación intelectual unamuniana. Nos referimos concretamente (con base en los estudios de Relegado García) al subjetivismo de Kierkegaard y al voluntarismo de Nietzsche y Schopenhauer, que se presentan como factores desencadenantes del alejamiento unamuniano del positivismo finisecular, que había alimentado su producción intelectual hasta el año de $1897^{6}$. De Kierkegaard, Unamuno heredó los temas de la subjetividad y de la salvación de la consciencias individuales; de Nietzsche, la voluntad de ser; y de Schopenhauer la identificación de la consciencia como voluntad y sufrimiento. Con base en dichas influencias la consciencia viviente unamuniana se ha constituido a partir de la afirmación de un subjetivismo individual, de rasgos voluntaristas expresados en el deseo de ser que, al estar polarizado por la preocupación de ultratumba, se ha plasmado en términos de dolor y sufrimiento.

El problema de la sustancialidad del alma personal constituyó uno de los centros de la reflexión unamuniana, como lo demuestra el capítulo V de su Del sentimiento trágico de la vida, de 1913, titulado significativamente «Disolución racional». En este aspecto particular, en el que está en cuestión saber si para el rector salmantino la consciencia viviente es o no una sustancia, el título nos parece decisivo a la hora

${ }^{5}$ «La conciencia no es para Unamuno, como para los filósofos anteriores, algo puramente presentacional y abstracto, sino el producto del dolor, la realidad sentimental más directa, descubierta en la vida personal misma: ser hombre es, no sólo saber el mundo por la conciencia pensante, no sólo saberse como sujeto [...], sino sentir esas realidades y sentirse uno a sí mismo dolorosamente, como centro indivisible en que lucha la realidad dual sujeto-objeto en toda su temporalidad encaminada hacia la muerte. Ser hombre es, pues, tener conciencia dolorosa de la temporalidad» (Blanco Aguinaga 1959; 20-21).

${ }^{6}$ «La reacción de Unamuno contra el positivismo y el racionalismo en los años que siguen a la crisis del 97 le inclinaron hacia una visión subjetiva y voluntariosa del Universo, en la que le habían precedido, además de Kierkegaard, Schopenhauer y Nietzsche, enemigos declarados los tres del idealista y racionalista Hegel» (Regalado García 1968; 113). 
de determinar su posición. Quizás por no fijarse en ello un conjunto de autores, entre de los cuales destaca F. Meyer, se ha equivocado en la exégesis del texto unamuniano al punto de sostener que en Unamuno la consciencia no es una sustancia ${ }^{7}$. La razón de su equívoco habrá que buscarla en el propio texto de Unamuno, que oscila entre la afirmación de la consciencia como sustancia y la negación de dicho predicado. La dificultad de identificar dichos conceptos es tanto mayor cuanto Ferrater Mora, en la década de los 80, afirma que la noción de consciencia en Unamuno se desvincula de la concepción tradicional de la misma ${ }^{8}$. En otra línea de interpretación se ubica Cerezo Galán que, en los 90, basado en la distinción kantiana entre filosofía práctica y teórica, ha afirmado que si, desde un punto de vista teórico, no puede predicarse la noción de sustancia con respecto al concepto de consciencia en Unamuno (en esto reitera la interpretación anterior), desde un punto de vista práctico, a contrario sensu los mencionados conceptos son tanto co-extensibles como correlativos ${ }^{9}$. Con dicha interpretación,

\footnotetext{
7 «La idea de sustancia participa en Unamuno de la ambigüedad y de la contradicción que son la forma misma del ser. Mas, a pesar de todo, parece a primera vista que nos encontramos, por el contrario, frente a una situación sin equívoco alguno. En efecto: "Lo único de veras real es lo que siente, sufre, compadece, ama y anhela, es la conciencia; lo único sustancial es la conciencia". La consecuencia que se deduce de esto es que todo lo que no es conciencia es, ante la conciencia, mera apariencia, y que toda realidad que no es conciencia es «fenoménica y aparencial», como repite Unamuno en varias ocasiones. Parece, pues, que nos encontramos en presencia de una especie de espiritualismo idealista de una factura totalmente clásica. [...] Pero la verdad no es tan simple como parece, y se encuentra ya uno con ciertas dificultades para poder encasillar en este cuadro afirmaciones como las siguientes: "La doctrina pretendida racional de la sustancialidad del alma y de su espiritualidad..., no nació sino de que los hombres sentían la necesidad de apoyar en la razón su incontrastable anhelo de inmortalidad". Aquélla es un conjunto de "sofisterías" y "no resiste la crítica". Y Unamuno se pone al lado de Hume, al afirmar que "lo que llamamos alma no es nada más que un término para designar la conciencia individual". La noción "racional" de sustancia no conviene al alma y ésta no es, por tanto, a lo menos en este sentido, una sustancia» (Meyer 1962; 69-70).

8 «Hay razones que abonan la presunción de que para Unamuno ciertas «cosas» -lo que quiere decir las más de las veces ciertos "rasgos" o ciertas cualidades- son reales, y otras no, y hasta la hipótesis de que algunas "cosas" ("rasgos" o "cualidades") son fundamentalmente, esto es, "radicalmente" reales. Lo único que no debe hacerse para confirmar, o desconfirmar, estas suposiciones es traducir las ideas, o los sentimientos, de Unamuno al respecto a términos más o menos tradicionalmente filosóficos. De hacerlo así, los resultados serían magros. Tendríamos que reconocer, por ejemplo, que Unamuno era un dechado de confusión, pues lo que proclamaba a veces como realidad suprema -"el hombre de carne y hueso" resultaba ser, según ya vimos, una especie de "ficción" creada por un "soñador", y no se ganaba mucho con agregar que justa y precisamente por ello era "real", o viceversa» (Ferrater Mora 1985; 130).

9 «No se puede afirmar, pues, que la unidad de la conciencia sea la de una sustancia. A primera vista esta conclusión parece chocar frontalmente con un leit-motiv del pensamiento de Unamuno: "lo que no es conciencia [...] nos es más que apariencia. Lo único de veras real es lo que siente, sufre y compadece, ama y anhela, es la conciencia; lo único sustancial es la conciencia" (VII, 201). Sería
} 
el pensamiento unamuniano se hace más comprensible en tanto que se obvia su contradicción latente. De ahora en adelante se comprende que la negación de la sustancialidad de la consciencia viviente resulta del ejercicio de la razón teórica sobre dicho tema mientras que su afirmación tiene origen en el marco existencialista y subjetivista en el que intencionadamente se ubica el autor. No nos extraña, pues, que en la obra unamuniana la negación de la sustancialidad de la consciencia tenga lugar en el susodicho capítulo, como tampoco que su afirmación se haga en los siguientes términos en el capítulo VII, titulado sugestivamente «Amor, dolor, compasión y personalidad»:

¿Y qué es la noción misma de sustancia, sino objetivación de lo más subjetivo, que es la voluntad o la conciencia? Porque la conciencia, aun antes de conocerse como razón, se siente, se toca, se es más bien como voluntad, y como voluntad de no morir (Unamuno 1969; VII, 194-195).

Más allá del problema de la sustancialidad de la consciencia viviente que se ubica, como el propio autor lo indica, en un plano nouménico y, por ende, inaccesible al pensamiento abstracto y racional $^{10}$, nos encontramos con el problema de su soporte ontológico, que aporta más significaciones a la hora de valorar la propuesta unamuniana. Para Unamuno, la consciencia no es una realidad que esté agregada al cuerpo humano como algo ontológicamente subsidiario, sino que es más bien el propio cuerpo con sus estados de consciencia. Aquí, la identificación de la consciencia con el cuerpo constituye lo esencial de

ingenuo creer que se trata de otro sentido de sustancia, en un uso libre o literario de esa categoría, o bien cargar el tema del gusto unamuniano por la contradicción. Más bien habría que pensar que no se trata del mismo sentido de "conciencia", pues en un caso se refiere a la teórica, que para Unamuno es puramente fenoménica, y en otro a la práctica, más próxima a la categoría de serse como hacer por ser. Lo decisivo es que Unamuno suspende, al modo kantiano, el valor teórico metafísico o trascendente de la categoría de sustancia, para dotarla de significación práctica moral» (Cerezo Galán 1996; 404).

10 «La unidad de la conciencia no es para la psicología científica -la única racional- sino una unidad fenoménica. Nadie puede decir que sea una unidad sustancial. Es más aún, nadie puede decir que sea una sustancia. Porque la noción de sustancia es una categoría no fenoménica. Es el númeno y entra, en rigor, en lo inconcebible» (Unamuno VII1969; VII, 160). 
la propuesta del autor ${ }^{11}$, que en términos generales se desvincula de la especulación católico-escolástica y de la propia modernidad filosófica en su vertiente más racionalista. Con esta toma de posición Unamuno acaba por dignificar de su realidad tan rehusada por la Iglesia Católica hasta finales del siglo XIX y principios del XX. En base a dicho alejamiento, Unamuno se acercará al pensamiento romántico, que ha alimentado su curiosidad intelectual a partir de los últimos años de bachillerato, en Bilbao, así como a Schopenhauer que concibe el cuerpo, en su dimensión subjetiva, como algo habitado por dentro. En suma, para Unamuno, el cuerpo es una realidad que piensa, quiere y siente (ver Unamuno 1969; VII, 158).

Preguntarle a uno por su yo, es como preguntarle por su cuerpo. $Y$ cuenta que al hablar del yo, hablo del yo concreto y personal; no del yo de Fichte, sino de Fichte mismo, del hombre Fichte (Unamuno 1969; VII, 113).

En cuanto al tema de la subjetividad carnal, cabría aún poner de relieve que, en Unamuno, las categorías de unidad y de continuidad constituyen los elementos fundamentales de la consciencia viviente considerada a partir de las coordenadas del tiempo y del espacio. Por la categoría de la unidad, la consciencia viviente puede distinguirse de su entorno físico y espiritual sobre la base de su cuerpo y propósito ${ }^{12}$, es decir, en función de su ipseidad psicosomática, mientras

\footnotetext{
11 «La conciencia individual humana depende de la organización del cuerpo, cómo va naciendo poco a poco, según el cerebro recibe las impresiones de fuera; cómo se interrumpe temporalmente durante el sueño, los desmayos y otros accidentes, y como todo nos lleva a conjeturar racionalmente que la muerte trae consigo la pérdida de la conciencia. Y así como antes de nacer no fuimos ni tenemos recuerdo alguno personal de entonces, así después de morir no seremos. Esto es lo racional» (Unamuno 1969; VII, 156).

12 «Lo que determina a un hombre, lo que le hace $u n$ hombre, uno y no otro, el que es y no el que no es, es un principio de unidad y un principio de continuidad. Un principio de unidad primero, en el espacio, merced al cuerpo, y luego en la acción y en el propósito. Cuando andamos, no va un pie hacia adelante, el otro hacia atrás: ni cuando miramos mira un ojo al Norte y el otro al Sur, como estemos sanos. En cada momento de nuestra vida tenemos un propósito, y a él conspira la sinergia de nuestras acciones. Aunque al momento siguiente cambiemos de propósito. Y es en cierto sentido un hombre tanto más hombre, cuanto más unitaria sea su acción. Hay quien en su vida no persigue sino un solo propósito, sea el que fuere» (Unamuno VII, 113).
} 
que por la categoría de la continuidad la consciencia viviente puede mantenerse una consigo misma a partir de las realidades de la memoria y de la esperanza, puesto que el pasado y el futuro se unifican en el presente fundamentados en la relación recíproca de dichas realidades ${ }^{13}$. En este sentido, lo fundamental de la reflexión unamuniana consiste en hacer patente la importancia de la noción de alteridad en la formación y constitución de la propia consciencia viviente, dado que para Unamuno esta supone dos discontinuidades ontológicas: la primera en el flujo temporal, por cuanto el yo-pasado, presente y futuro no son idénticos entre sí, y la segunda en su propia constitución espiritual como resultado de la influencia del mundo externo sobre la consciencia humana. Todo sucede como si la identidad se alimentara de la propia alteridad en su formación y constitución ontológicas. Cabría puntualizar, por último, que dicha conceptualización, bajo un planteamiento existencial, tiene aún la virtualidad de maximizar los conceptos ético-religiosos de libertad y obra, dado que permite enfocar la existencia humana como un hacerse continuo, cuya finalidad se plasma en la formación de la identidad personal.

\section{Consciencia: subjetividad histórica}

Si hay un aspecto dentro de la vida del autor que determina la preocupación por el tema de la consciencia histórica, este es sin duda el de Unamuno escritor. En este aspecto no podemos prestar mayor asentimiento interpretativo a Cerezo Galán, cuando afirma que este mismo hecho supone una nueva existencia ontológica presente en la pervivencia por la palabra ${ }^{14}$. Es que en la relación identidad-alteridad o, si

${ }^{13}$ «Y un principio de continuidad en el tiempo. Sin entrar a discutir -discusión ociosa- si soy o no el que era hace veinte años, es indiscutible, me parece, el hecho de que el que soy hoy proviene, por serie continua de estados de conciencia, del que era en mi cuerpo hace veinte años. La memoria es la base de la personalidad individual, así como la tradición lo es de la personalidad colectiva de un pueblo. Se vive en el recuerdo y por el recuerdo, y nuestra vida espiritual no es, en el fondo, sino el esfuerzo de nuestro recuerdo por perseverar, por hacerse esperanza, el esfuerzo de nuestro pasado por hacerse porvenir» (Unamuno 1969; VII, 113).

14 «Ser escritor, en sentido radical y pleno, exhaustivamente, es decir, de cuerpo entero y de toda la vida, como fue Unamuno, supone una forma integral de ser hombre: existir en la palabra» (Cerezo Galán 1996; 31). 
se quiere, en la relación autor-lector, Unamuno escritor vive tanto de la lectura de obras ajenas como pervive por la lectura de sus propias obras. Hecho particularmente decisivo en el marco de la literatura autobiográfica, dentro del que intencionadamente se ubica el autor, pero con consecuencias decisivas para el rector salmantino a raíz de su planteamiento ontológico. En efecto, dentro de un pensamiento filosófico-literario, que asume como cimientos ontológicos la doctrina spinoziana del conatus y la struggle for live darwiniana, la persistencia del ser del escritor va ineludiblemente vinculada a su producción literaria, que es inmediatamente concebida como posibilidad de cristalización de la consciencia individual intrahistórica. En ese proceso de cristalización la subjetividad carnal se metamorfosea en la subjetividad histórica, ganando nuevas connotaciones e implicaciones ontológicas en razón de dicho proceso.

La primera metamorfosis que sufre el concepto de consciencia está vinculada a la afirmación de una nueva doctrina del ser, que exige una nueva concepción de sustancia. Al independizarse la consciencia del cuerpo en que tuvo su origen se cristaliza en registros históricos como ensayos, novelas, dramas y poesías, supone una concepción de ser como actividad que Unamuno ha expresado por primera vez de forma bastante contundente en su Vida de don Quijote y Sancho, de 1905, cuando afirma que «sólo existe lo que obra en cuanto obra». Dicha idea es reiterada ocho años más tarde en su obra de mayor aliento filosófico (Del sentimiento trágico de la vida, 1913), cuando sostiene que «ser es obrar» ${ }^{15}$. En este aspecto Julián Marías está en lo cierto al afirmar que en Unamuno hay un rechazo claro del sustancialismo tradicional a favor de una interpretación dinámica del ser ${ }^{16}$. Con este cambio

${ }^{15}$ «Luego que un hombre se murió y pasó acaso a memoria de otros hombres, ¿en qué es más que una de esas ficciones poéticas de que abomináis? Vuestra merced debe saber que por sus estudios lo de operari sequitur esse, el obrar se sigue al ser, y yo le añado que sólo existe lo que obra y existir es obrar, y si Don Quijote obra, en cuantos le conocen, obras de vida, es don Quijote mucho más histórico y real que tantos hombres, puros nombres que andan por esas crónicas que vos señor licenciado tenéis por verdaderas. Sólo existe lo que obra» (Unamuno 1968; III, 131-132).

16 «Desde estos supuestos, Unamuno rechaza el "sustancialismo" tradicional, que hace consistir la realidad en lo que está ahí, fuera de mí, y permanece y subsiste. [...] Y esta interpretación activa del ser lo va a conducir, por una parte, a afirmar la realidad primaria de lo más activo, la vida misma y la conciencia 
teórico-conceptual el ser de las cosas deja de tener independencia exterior respecto al sujeto cognoscente para pasar a estarle directamente subordinado ${ }^{17}$. No nos extraña, pues, que el autor se aleje del adagio latino operari sequitur esse, proponiendo una clara inversión de los términos, al modo cartesiano, hasta el punto de que la existencia quede vinculada a su actualización subjetiva o intersubjetiva ${ }^{18}$. La radicalización de este planteamiento ontológico surge cuando Unamuno, basado en dicha concepción dinámica del ser, concede existencia real a los personajes ficticios que rivalizan con sus autores su preeminencia ontológica. Todo sucede como si los entes de ficción, en cuanto ecos de la realidad intrahistórica del autor, se constituyesen como sustrato ontológico de la realidad histórica de sus creadores.

- No, no existe más que como ente de ficción; no eres, pobre Augusto, más que un producto de mi fantasía y de las de aquellos de mis lectores que lean el relato que de tus fingidas venturas y malandanzas he escrito yo; tú no eres más que un personaje de novela o de nivola, o como quieras llamarle. Ya sabes, pues, tu secreto [...].

- No sea, mi querido don Miguel -añadió-, que sea usted, y no yo, el ente de ficción, el que no existe en realidad, ni vivo, ni muerto... No sea que usted no pase de ser un pretexto para que mi historia llegue al mundo (Unamuno 1967; II, 666).

La correcta comprensión del juego dialéctico que mantienen entre sí la subjetividad carnal y la subjetividad histórica nos permite percibir tres aspectos de discontinuidad ontológica fundamentales en el pensamien-

\footnotetext{
humana; y por otra parte, a reconocer la realidad de todo lo que obra. Lo cual lleva, a su vez, a completar su teoría de la sustancialidad de la persona consciente y a pasar, desde ella, a la afirmación de la realidad del ente de ficción» (Marías 1950; 167-168).

17 «¿Qué es, en efecto, existir y cuándo decimos que una cosa existe? Existir es ponerse algo de tal modo fuera de nosotros, que precediera a nuestra percepción de ello y pueda subsistir fuera cuando desaparezcamos. ¿Y estoy acaso seguro de que algo me precediera o de que algo me ha de sobrevivir? ¿Puede mi conciencia saber que hay algo fuera de ella? Cuando conozco o puedo conocer está en mi conciencia. No nos enredemos, pues, en el insoluble problema de otra objetividad de nuestras percepciones, sino que existe cuanto obra, y existir es obrar» (Unamuno 1969; VII, 225).

18 «El viejo adagio de que operari sequitur esse, el obrar se sigue al ser, hay que modificarlo diciendo que ser es obrar» (Unamuno 1969; VII, 196).
} 
to unamuniano. Nos referimos en concreto a las realidades de la consunción, enajenación y hermenéutica. Pese el hecho de que aquí, como lo puntualiza Cerezo Galán, la hipocresía pudiese presentarse como un factor de discontinuidad ontológica ${ }^{19}$, por cuestiones metodológicas sólo analizaremos dicha realidad con base en la disyunción onto-gnoseológica que mantienen entre sí los conceptos clásicos de realidad y apariencia.

El primer momento de discontinuidad ontológica, que consubstancia el paso de la consciencia viviente a la consciencia historia, está presente en el concepto de consunción, tal como Unamuno lo concibe e interpreta en su obra Cómo se hace una novela, de 1927. En este aspecto, creemos que la propuesta interpretativa de Carlos París es particularmente significativa al identificar dicho concepto con la noción griega de anquilosamiento $(\alpha \gamma \kappa v \lambda \omega \sigma \iota)$, que significa etimológicamente pérdida de movimiento ${ }^{20}$. En base a dicha interpretación, se percibe una diferencia fundamental entre la consciencia viviente y la histórica como resultado de su relación con dos nociones bien distintas de temporalidad. Si la consciencia viviente se ubica en un mundo heracliteanamente temporal y dinámico ${ }^{21}$, donde las consciencias individuales evolucionan espiritualmente a lo largo de las diversas sucesiones temporales, por el contrario la consciencia histórica se ubica en un mundo parmenidianamente atemporal y estático ${ }^{22}$. De este modo, el paso de la consciencia viviente a la consciencia histórica supone una discontinuidad ontológica radical presente en la fijación y eternización de un determinado momento de la vida intrahistórica.

\footnotetext{
19 «Junto al riesgo de la enajenación, amenaza otro no menos terrible. La contrapartida de esta exposición, tan sincera y apasionada en la obra, era paradójicamente la conciencia de estar haciendo teatro. No bastan las motivaciones psicológicas para dar cuenta de ello. Son razones estructurales, inherentes a la misma expresión: ésta presenta al yo, pero de un modo figurativo, es decir, en persona que es equívocamente rostro y máscara» (Cerezo Galán 1996; 33).

${ }_{20}$ «En el primer orden, la producción literaria es intrínsecamente consunción, anquilosamiento» (París 1989; 47).

${ }^{21}$ Heráclito, Fr. 12: «Para os que entrarem nos mesmos rios, outras e outras são as águas que por eles correm... Dispersam-se e... reúnem-se... juntas vêm e para longe flúem... aproximam-se e afastam-se» (Kirk \& Raven 1994; 202).

${ }^{22}$ Parménides, Fr. 8: «Mas, imobilizado nos limites de potentes grilhetas, existe sem começo ou interrupção, já que geração e destruição se transviaram para muito longe, e a convicção verdadeira as repeliu. Ao manter-se o mesmo e no mesmo lugar, em si mesmo repousa e assim firme há-de permanecer. Pois a forte necessidade o retém nas grilhetas de um limite, que de ambos os lados o encerra» (Kirk \& Raven 1994; 262).
} 
Eso que se llama en literatura producción -escribe el bilbaíno- es un consumo, o más preciso: una consunción. El que pone por escrito sus pensamientos, sus ensueños, sus sentimientos, los va consumiendo, los va matando. En cuanto un pensamiento nuestro queda fijado por la escritura, expresado, cristalizado, queda ya muerto, y no es más nuestro que será un día bajo tierra nuestro esqueleto. La historia, lo único vivo, es el presente eterno, el momento huidero que se queda pasando, que pasa quedándose, y la literatura no es más que muerte. Muerte de que otros pueden tomar vida. Porque el que lee una novela puede vivirla, revivirla $-y$ quien dice una novela dice una historia-, y el que lee un poema, una criatura -poema es criatura y poesía creación- puede re-crearlo (Unamuno 1970; VIII, 710-711).

El segundo momento de discontinuidad ontológica se refiere al concepto de enajenación (del lat. in y alienāre), que, atendiendo a su origen etimológico y su a probable inspiración bíblica, aunque con ello el autor no olvidase la polisemia del concepto ${ }^{23}$, debe ser concebido como un momento de pérdida de la identidad de la consciencia individual como resultado de su pervivencia en un mundo ontológicamente distinto del original. En este aspecto, concordamos con F. Meyer cuando afirma que, en Unamuno, la realización histórica de la subjetividad carnal debe ser pensada como el resultado de un proceso de enajenación, que materializa la pérdida de la interioridad en un mundo externo que la despersonaliza ${ }^{24}$. Asimismo, la metamorfosis de la consciencia viviente en consciencia histórica se hace una vez más a costa de una nueva pérdida de identidad que se concreta a partir de la cristalización de la subjetividad carnal en un registro literario o artístico. De este modo, si el movimiento anterior suponía la fijación

\footnotetext{
${ }^{23}$ Varios son los ámbitos en que dicho concepto suele ser empleado: en el ámbito jurídico se refiere a la transmisión del derecho de propiedad; en el ámbito psiquiátrico al sentido de pérdida de la razón; y en el ámbito fisiológico a la pérdida de sensaciones o a la paralización motora.

${ }^{24}$ «Todo acto, es decir, toda realización de mi yo, es también una enajenación; al hacerme yo a mí mismo, me pierdo en medio del mundo, no puedo hacerme sino perdiéndome, no puedo vivir sin morir también a mí mismo» (Meyer 1962; 79).
} 
de la vida intrahistórica, esencialmente temporal y dinámica, en un mundo estático e inmoble, el presente movimiento supone una nueva discontinuidad ontológica presente en la cristalización de la consciencia individual en una realidad ontológica distinta de la original. O dicho en otros términos, si la subjetividad carnal es expresión de un cuerpo que piensa, siente y quiere, la subjetividad histórica, por el contrario, supone el lenguaje como soporte ontológico de la subjetividad viviente original. En este tránsito de una subjetividad a otra, el hecho de que la consciencia histórica tenga como sustrato ontológico el propio lenguaje humano, que es naturalmente comunal, supone la radicalización de dicha discontinuidad ontológica, ya que el contenido de la consciencia intrahistoria, esencialmente individual, quedará alienado en su carácter originario.

No, no comunica uno lo que quería comunicar -pensó-; apenas un pensamiento encarna en palabra, y así revestido sale al mundo, es de otro, o más bien no es de nadie por ser de todos. La carne de que se reviste el lenguaje es comunal y es externa; engurruñe el pensamiento, lo aprisiona y aun lo trastorna y contrahace. No, él no había querido decir aquello, él nunca había pensado aquello (Unamuno 1966; I, 1138).

Y el tercero y último momento de discontinuidad ontológica se refiere al concepto de hermenéutica. Pero con una diferencia en relación con los dos anteriores, ya que en el juego dialéctico que mantienen entre sí los conceptos de consciencia viviente e histórica, el movimiento de discontinuidad pasa a ser enfocado a la inversa: de la historia hacia la intrahistoria. Se trata, pues, de un retorno de la consciencia individual al mundo intrahistórico, donde las subjetividades vivientes son capaces de actualizar las subjetividades históricas. Dentro de este horizonte filosófico, Schleiermacher y Renán tienen una influencia determinante en la formación intelectual del autor, como lo demuestra la aceptación unamuniana de dos categorías fundamentales de la hermenéutica con- 
temporánea. Nos referimos concretamente a las nociones de prejuicio ${ }^{25}$ y contrasentido ${ }^{26}$. En esta toma de posición puede percibirse un alejamiento intelectual unamuniano respecto de Avenarius ${ }^{27}$ y Comte $^{28}$, que ubicados dentro del marco del positivismo filosófico, se oponen a una concepción antropomórfica y mitopeica del lenguaje, concebido como una realidad ético-social en razón de su condicionamiento a las coordenadas del tiempo y del espacio ${ }^{29}$, que el rector salmantino

${ }^{25}$ «El pensamiento reposa en pre-juicios y los pre-juicios van en la lengua. Con razón adscribía Bacon al lenguaje no pocos errores de los idola fori. Pero ¿cabe filosofar en pura álgebra o siquiera en esperanto? No hay sino leer el libro de Avenarius de crítica de la experiencia pura -reine Erfahrung-, de esta experiencia prehumana, o sea inhumana, para ver adónde puede llevar eso. Y Avenarius mismo, que ha tenido que inventarse un lenguaje, lo ha inventado sobre tradición latina, con raíces que lleva en su fuerza metafórica todo un contenido de impura experiencia, de experiencia social humana. // Toda filosofía es, pues, en el fondo, filología. Y la filología, con su grande y fecunda ley de las formaciones analógicas, da su parte al azar, a lo irracional, a lo absolutamente inconmensurable. La historia no es matemática ni la filosofía tampoco. ¡Y cuántas ideas filosóficas no se deben en rigor a algo así como rima, a la necesidad de colocar un consonante! En Kant mismo abunda no poco de esto, de simetría estética, de rima» (Unamuno1969; VII, 291).

${ }^{26}$ Fragmento de E. Renán citado por Unamuno: «Para el filólogo un texto no tiene más que un sentido; pero, para el espíritu que ha puesto en este texto su vida y sus complacencias todas, para el espíritu humano que a cada hora experimenta nuevos anhelos, la interpretación escrupulosa del filólogo no puede bastarle. Es menester que el texto que ha adoptado resuelva todas sus dudas, satisfaga todos sus deseos. De aquí una especie de necesidad del contrasentido en el desarrollo filosófico y religioso de la humanidad. El contrasentido, en las épocas de autoridad, es como el desquite que toma el espíritu humano contra la infalibilidad del texto oficial... ¿Qué sería de la humanidad si desde hace dieciocho siglos hubiera entendido la Biblia con los léxicos de Gesenius o de Bretscheider? No se crea nada con un texto que se comprende demasiado exactamente. La interpretación verdaderamente fecunda, que en la autoridad aceptada de una vez para siempre sabe hallar respuesta a las exigencias sin cesar renacientes de la naturaleza humana, es obra de la conciencia más que de la filología» (Unamuno 1968; III, 372-373).

${ }^{27}$ «Y de nada sirve querer suprimir ese proceso mitopeico o antropomórfico y racionalizar nuestro pensamiento, como si se pensara sólo para pensar y conocer, y no para vivir. La lengua misma, con la que pensamos, nos lo impide. La lengua, sustancia del pensamiento, es un sistema de metáforas a base mítica y antropomórfica. Y para hacer una filosofía puramente racional habría que hacerla por fórmulas algebraicas o crear una lengua -una lengua inhumana, es decir, inapta para las necesidades de la vidapara ella, como lo intentó el doctor Ricardo Avenarius, profesor de filosofía en Zurich, en su Crítica de la experiencia pura (Kritik der reinen Erfahrung), para evitar los preconceptos. Y este vigoroso esfuerzo de Avenarius, el caudillo de los empiriocriticistas, termina en rigor en puro escepticismo. Él mismo nos lo dice al final del prólogo de la susomentada obra: "Ha tiempo que desapareció la infantil confianza de que nos sea dado hallar la verdad; mientras avanzamos, nos damos cuenta de sus dificultades, y con ello del límite de nuestras fuerzas. ¿Y el fin?... ¡Con tal de que lleguemos a ver claro en nosotros mismos!”» (Unamuno 1969; VII, 195).

${ }^{28}$ «En vano Comte declaró que el pensamiento humano salió ya de la edad teológica y está saliendo de la metafísica para entrar en la positiva; las tres edades coexisten y se apoyan, aun oponiéndose, unas en otras. El flamante positivismo no es sino metafísico cuando deja de negar para afirmar algo, cuando se hace realmente positivo, y la metafísica es siempre, en su fondo, teología, y la teología nace de la fantasía puesta al servicio de la vida, que se quiere inmortal» (Unamuno1969; VII, 194).

${ }_{29}$ «La representación brota del ambiente, pero el ambiente mismo es quien le impide purificarse y elevarse. Aquí se cumple el misterio de siempre, el verdadero misterio del pecado original, la condenación de la idea al tiempo y al espacio, al cuerpo» (Unamuno 1966; I, 788). 
defiende siguiendo las huellas de $\operatorname{Vico}^{30}$. Ahora bien, a partir de su alejamiento de los ideales positivistas que han animado la primera etapa de su formación intelectual (1884-1897), Unamuno se acercará a la hermenéutica contemporánea, percibiendo en la relación autor-lector una discontinuidad ontológica que se concreta a partir de un vitalismo, de carácter ético-religioso, en el que el concepto de fusión de horizontes se presenta como condición de posibilidad de aumentar la espiritualidad de las subjetividades intrahistóricas. Con esta toma de posición, el rector salmantino suspende la posibilidad de reconstrucción de la subjetividad carnal primitiva para abrirse a una perspectiva filosóficohermenéutica de carácter eminentemente vitalista ${ }^{31}$.

\section{Consciencia: apariencia y realidad}

Dentro del pensamiento unamuniano, el tema ontológico concerniente al binomio apariencia-realidad tiene una doble acepción: la primera está vinculada a la doctrina clásica de la sustancialidad del alma personal y la segunda a la distinción onto-gnoesológica kantiana entre lo nouménico y lo fenoménico.

La primera utilización que el rector salmantino hace de dicho binomio, como lo percibe bien Meyer, irrumpe con la radicalización que Unamuno hace del concepto de consciencia al punto de rehusarle toda sustancialidad ${ }^{32}$. Para el bilbaíno, toda consciencia intrahistórica no es más que apariencia ya que, al ser coexistente con el cuerpo que

${ }^{30}$ «Juan Bautista Vico, con su profunda penetración estética en el alma de la Antigüedad, vió que la filosofía espontánea del hombre era hacerse regla del universo guiado por istinto d'animazione. El lenguaje, necesariamente antropomórfico, mitopeico, engendra el pensamiento» (Unamuno 1969; VII, 193).

31 «Las cosas claras, amigo Pitollet, y nada de falsas modestias. Cervantes encontró al Quijote en el alma de su pueblo y nos le mostró; yo he vuelto a encontrarle, merced a su libro, y creo que él no lo entendió bien y he vuelto a presentarlo. Él hizo su Quijote y yo he hecho el mío. Si éste coincide o no con aquél en todo, y si es o no fiel reflejo de él, es cosa que no hace al caso. La cuestión es si mi Quijote en sí, tiene o no, eficacia espiritual. Si me dicen que no he entendido el quijote de Cervantes, responderé que Cervantes ni aún vislumbró el mío» (Unamuno1968; III, 13).

32 «Rehusase ahora la sustancialidad a toda consciencia que no sea eterna y eternamente consciente de su eternidad; pero si es verdad que toda consciencia de ser implica, como hemos visto, limitación y finitud, es preciso entonces afirmar que no puede existir una conciencia eterna. He ahí, pues, que nuestra conciencia, al no ser eterna, no es más que una mera apariencia, y que todas las otras cosas no son, para esta apariencia más que apariencias también. Así parece que todo el ser se presenta vacío de toda sustancialidad y se ve condenado a una apariencialidad» (Meyer 1962; 70). 
la sustenta, es temporalmente finita y, por ende, una realidad perecedera. La comprensibilidad de la posición unamuniana tiene su asiento filosófico en el tema clásico de la inmortalidad del alma personal que irrumpe con el pensamiento platónico en la antigüedad clásica. Sin embargo, Unamuno al revés del griego, se colocar bajo el horizonte de la fenomenología contemporánea y termina por rechazar todos los postulados racionalistas del alma como sustancia simple e incorruptible, dado que dicho horizonte filosófico tiende a negar el concepto de sustancia en cuanto categoría estrictamente nouménica ${ }^{33}$.

La segunda acepción de dicho binomio es la que más se relaciona con el presente estudio. Si se analiza con algún detalle su obra Tres novelas ejemplares y un prólogo, de 1921, pronto se hará patente que la gran cuestión filosófica unamuniana consiste en la necesidad de determinar la esencia del verdadero yo, de fijar su ser real por oposición a su ser aparencial. Ahora bien, dos son las interpretaciones que se coligen de los comentarios realizados a la obra del autor. La primera es la de Julián Marías que, al arrancar de la distinción unamuniana entre ser dinámico y estático considera que, en Unamuno, lo real es lo que se refiere a la vida humana como resultado de ser esencialmente íntima y dinámica. Con esta interpretación, se acerca a la posición defendida por el propio autor en la mencionada obra de 1921, donde concibe, con base en sus lecturas de Schopenhauer y Spinoza, el yonouménico como voluntad y deseo de persistencia ${ }^{34}$. Otra interpretación es la que parece sostener A. Zubizarreta cuando, al centrar sus análisis en Cómo se hace una novela, de 1927, afirma que la consciencia real debe ser interpretada como la consciencia histórica, porque sólo esta concreta las posibilidades del ser de cada hombre o, en sus

${ }^{33}$ «Lo que no es conciencia, y conciencia eterna, conciente de su eternidad y eternamente conciente, no es nada más que apariencia» (Unamuno 1969; VII, 201).

34 «Quedamos, pues, [...] en que el hombre más real, realis, más res, más cosa, es decir, más causa sólo existe lo que obra-, es el que quiere ser o el que quiere no ser, el creador. Sólo que este hombre que podríamos llamar, al modo kantiano, numénico, este hombre volitivo e ideal -de idea-voluntad o fuerzatiene que vivir en un mundo fenoménico, aparencial, racional, en el mundo de los llamados realistas. Y tienen que soñar la vida que es sueño. Y de aquí, del choque de esos hombres reales, unos con otros, surgen la tragedia y la comedia y la novela y la nivola» (Unamuno 1967; II, 974). 
palabras, sólo esta realiza su persona, su eternidad ${ }^{35}$. Cabría señalar que, dentro del pensamiento del autor, dicha disensión hermenéutica es tanto más significativa en la medida en que Unamuno se mueve continuadamente entre las categorías de historia e intrahistoria. De este modo, cuando el autor se acerca más a la noción de interioridad tiende a afirmar que el verdadero yo es el yo-nouménico o intrahistórico, mientras que cuando se acerca más a la noción de exterioridad tiende a afirmar que el verdadero yo es el yo-fenoménico o histórico. Pese a la presente contradicción, que arranca del hecho de que su pensamiento se estructura metodológicamente a partir de la afirmación alternativa de los contradictorios, creemos que es posible superarla con base en la afirmación simultánea de los mismos que caracteriza la última etapa de su formación intelectual (1931-1936), al afirmar que la consciencia viviente, en su carácter nouménico, es verdadera en cuanto se constituye como condición de posibilidad de la consciencia histórica, y que esta es igualmente verdadera en cuanto se presenta como concretización de las posibilidades del ser de cada individuo y como única puerta de acceso para el sujeto cognoscente en términos onto-gnoseológicos. De esta forma, nos alejamos de la interpretación de P. Ilie, cuando afirma que, en Unamuno, es imposible establecer el verdadero $\mathrm{yo}^{36}$, ya que partimos del supuesto de que la intrahistoria y la historia constituyen dos partes de la misma realidad y que am-

\footnotetext{
${ }^{35}$ «Partiendo de su situación concreta de desarraigado, imposibilitado de hacerse en España, escribe Cómo se hace una novela, que no sólo es una forma de hacer historia española y su propia historia en el sentido político, sino de realizar su persona, de hacer su eternidad» (Zubizarreta 1960; 201).

36 «It is impossible, then, to establish which self is the real one, or to aspire to any fulfillment of self. The equivocal entity called personality exists as a phenomenon, is interpreted by others and forged into a legend about us, and is contemplated by us as we ourselves make our autoleyenda. These three aspects are the main threads in the subtle web of contradictions felt by Unamuno in his writings. The first, serving as a reminder that the self is an objective reality, is a constant source of distress as we realize that no one can ever know who he is. The second, legendary self contains two facets. One is a voluntaristic impulse toward the future, in which we elaborate beforehand the performance of the person that we wish to be. The other facet is the mental image of our social projection now, in which the person that we think we are adopts an illusory form. That is, we view our social self in the arena of our own awareness, and we form a private interpretation of the drama enacted by this social self. It is illusory in that we can only imagine it to correspond with what correspond with that the other people see. But there is a third feature to personality in addition to being a phenomenon and a legendary self. There is also the legend that others have built up around us, and this too is determinate by several factors. As spectators, those people offer a perception of our present performance, the expression of which is nothing more than a chronicle of current history» (Ilie 1967; 75-76).
} 
bas, siendo correlativas, son igualmente legítimas y reales en términos onto-gnoseológicos. Asimismo, reanudando el concepto de hipocresía a partir de la lectura e interpretación que el propio autor le concede, podríamos decir que son tan reales el rostro como la máscara, puesto que son dos realidades indisociablemente vinculadas.

En definitiva, en Unamuno, dos son las acepciones del concepto de consciencia individual. La primera se vincula con la noción de subjetividad carnal y la segunda con la noción de subjetividad histórica. Dicha doble acepción tiene como génesis el concepto de consciencia colectiva que había animado las preocupaciones filosóficas del autor durante la primera etapa de su formación intelectual (1884-1897), y que se dividía en las categorías de historia e intrahistoria. Desde el punto de vista onto-gnoseológico, la doble acepción de la consciencia individual supone un vínculo correlativo, aunque no co-extensivo, entre ambas. Pues, del mismo modo que la consciencia histórica es el resultado de la concreción de algunas de las posibilidades de ser de la consciencia viviente, la subjetividad carnal aumenta o reduce su conjunto de posibilidades de ser a partir de la concreción de la consciencia histórica. Pese al hecho de su relación manifiestamente co-recíproca, Unamuno no siempre les ha concedido la misma importancia a lo largo de su extensa obra. Lo demuestra el hecho de que la consciencia viviente se constituya como el eje de la reflexión del autor durante la segunda etapa de su formación intelectual (1898-1913), y la consciencia histórica durante la tercera (1914-1930). Lo anterior fue resultado de una serie de motivaciones: en primer lugar, las de orden existencial, como su crisis espiritual del 97 y su destierro voluntario, en 1924, que le han acercado respectivamente a las susodichas nociones; $y$, en un segundo lugar, las de orden metodológico, ya que Unamuno acepta como método filosófico la afirmación alternativa de los contradictorios. En el cuarto período de su formación intelectual (1931-1936) dicha dicotomía es superada como resultado de su regreso a España. A partir de entonces el rector salmantino apuesta por la afirmación simultánea de los contradictorios, afirmando la historia e intrahistoria como partes de la misma realidad. 


\section{BIBLIOGRAFÍA}

Álvarez Gómez, M. (2003). Unamuno y Ortega: la búsqueda azarosa de la verdad. Madrid: Biblioteca Nueva.

Blanco Aguinaga, C. (1959). El Unamuno contemplativo. México: Colegio de México.

Cerezo Galán, P. (1996). Las máscaras de lo trágico. Filosofía y tragedia en Miguel de Unamuno. Madrid: Trotta.

Clavería, C. (1953). Temas de Unamuno. Madrid: Gredos.

Ferrater Mora, J. (1985). Unamuno: bosquejo de una filosofía. Madrid: Alianza Editorial.

Gómez Molleda, M. (1989). (ed.), Actas del Congreso Internacional. Salamanca: Ediciones Universidad de Salamanca.

Ilie, P. (1967). Unamuno an existencial view of self and society. Madison, Milwaukee y London: The University of Wisconsin Press.

Kirk, G. S. \& Raven, J. E. (1994). Os Filósofos Pré-Socráticos. Carlos Alberto Louro Fonseca (trad.), Lisboa: Fundação Calouste Gulbenkian.

Marías, J. (1950). Miguel de Unamuno. Buenos Aires: Espasa-Calpe.

Meyer, F. (1962). La ontología de Miguel de Unamuno. Madrid: Gredos, 1962.

Paredes Martín, M. (2000). «Conocimiento y realidad en Del sentimiento trágico de la vida». En: Cuadernos de la Cátedra de Miguel de Unamuno, 35 , 77-94.

París, C. (1989). Unamuno: estructura de su mundo intelectual. Barcelona: Anthropos.

Regalado García, A. (1968). El siervo y el señor. La dialéctica agónica de Miguel de Unamuno. Madrid: Gredos.

Unamuno, M de. (1967-1971). Obras Completas. Manuel García (ed.). Madrid.

Zubizarreta, A. F. (1960a). Tras las huellas de Unamuno. Madrid: Taurus. Zubizarreta, A. F. (1960b). Unamuno en su Nivola. Madrid: Taurus. 


\section{RESUMEN}

Realizaremos un estudio del concepto unamuniano de consciencia con base en las nociones ontológicas de historia e intrahistoria. Intentamos percibir la doble acepción del concepto de consciencia en Unamuno, considerando los principios ontológicos propios de la primera etapa de su formación que, bajo la trasmutación de su pensamiento de la exterioridad hacia la interioridad, se reestructuran en los conceptos de subjetividad carnal y subjetividad histórica. Dicha metodología se legitima en el trasfondo filosófico del pensamiento unamuniano, que se desvincula del concepto de consciencia colectiva a favor del concepto de consciencia individual. Consideramos importante la noción de sustancia que el autor concibe e interpreta en Vida de don Quijote y Sancho y Del sentimiento trágico de la vida. Con base en su existencialismo, de corte vitalista, los conceptos de apariencia y realidad asumen matices muy peculiares en la doble dimensión del concepto de consciencia, cuando se correlacionan con el conatus spinoziano.

Palabras clave: consciencia, sustancia, apariencia y realidad.

\section{ABSTRACT}

We'll study the Unamuno's concept of consciousness based on the ontological notions of history and intrahistory. We try to understand the double meaning of the Unamuno's concept of consciousness considering the own ontological principles from the first stage of his formation, which are restructured in the concepts of carnal subjectivity and historical subjectivity, under the transmutation of his thought from the exteriority to the interiority. This methodology is legitimized in the philosophical background of Unamuno's thought which is separated from the concept of collective consciousness in favor of the concept of individual consciousness. We'll consider important the notion of substance that the author conceives and interprets in Life of Don Quixote and Sancho and in Tragic sense of life. Based on his existentialism, of vitalist sort, the concepts of appearance and reality assume 
peculiar nuances in the double dimension of the concept of consciousness, when they are compared with the Spinoza's conatus.

Key words: consciousness; substance; appearance; reality. 